\title{
PENGUATAN KECERDASAN DIGITAL PEMUDA SEBAGAI BENTUK KETERLIBATAN DALAM TOTAL DIPLOMASI INDONESIA
}

\author{
Christy Damayanti dan Andika Drajat Murdani \\ Ilmu Hubungan Internasional, Universitas Slamet Riyadi. Email: christydhartono@gmail.com, \\ andika.drajat.m@gmail.com
}

\begin{tabular}{|c|c|}
\hline Info Artikel & Abstract \\
\hline \multirow{15}{*}{$\begin{array}{l}\text { Masuk: } \\
\text { Revisi: } \\
\text { Diterima: } \\
\text { Terbit: } \\
\text { Keywords: } \\
\text { Ditigal intelligence, } \\
\text { Indonesia, total diplomacy, } \\
\text { youth. }\end{array}$} & The digital age is driving the flow of information to move quickly and \\
\hline & change patterns of international relations. This condition affects the \\
\hline & development of total diplomacy schemes in supporting the \\
\hline & $\begin{array}{l}\text { achievement of Indonesia's diplomacy goals. In this program, we } \\
\text { take international relations students from Slamet Rivadi University }\end{array}$ \\
\hline & as target partners. This community service program wants to \\
\hline & support Indonesia's efforts to collaborate with digital media in total \\
\hline & diplomacy schemes with student youth agencies, through \\
\hline & Total Indonesian Diplomacy". The method used in this service \\
\hline & program was socialization and training. The expected output \\
\hline & $\begin{array}{l}\text { targets are (1) International Relations students can be involved in } \\
\text { total diplomacy positively, (2) students have the provision of digital }\end{array}$ \\
\hline & intelligence in accordance with the positive character of the nation \\
\hline & needed, (3) students are able to contribute to fostering a positive \\
\hline & image of Indonesia in the international eyes. $\mathrm{Tr}$ \\
\hline & \\
\hline & $\begin{array}{l}\text { video content made by them that was adjusted to the Indonesian } \\
\text { diplomacy mission. }\end{array}$ \\
\hline \multirow{6}{*}{$\begin{array}{l}\text { Kata kunci: } \\
\text { Kemapuan digital, } \\
\text { Indonesia, total diplomasi, } \\
\text { pemuda. }\end{array}$} & Abstrak \\
\hline & Era digital mendorong arus informasi untuk bergerak cepat dan \\
\hline & mengubah pola hubungan internasional. Kondisi ini mempengaruhi \\
\hline & pengembangan skema diplomasi total dalam mendukung \\
\hline & $\begin{array}{l}\text { pencapaian tujuan diplomasi Indonesia. Dalam program ini, kami } \\
\text { mengambil mahasiswa hubungan internasional dari Universitas }\end{array}$ \\
\hline & $\begin{array}{l}\text { Slamet Riyadi sebagai mitra kegiatan. Program pengabdian } \\
\text { masvarakat ini ingin mendukung upava Indonesia untuk }\end{array}$ \\
\hline \multirow{11}{*}{$\begin{array}{l}\text { P-ISSN: } 2598-2273 \\
\text { E-ISSN: } 2598-2281 \\
\text { DOI : } 10.33061\end{array}$} & berkolaborasi dengan media digital dalam skema diplomasi total \\
\hline & dengan agen pemuda pelajar, melalui upaya "Memperkuat \\
\hline & Kecerdasan Digital Pemuda sebagai Bentuk Kontribusinya pada \\
\hline & Diplomasi Total Indonesia". Metode yang digunakan dalam \\
\hline & Adapun target luaran yang diharapkan adalah (1) siswa Hubungan \\
\hline & Internasional dapat terlibat dalam diplomasi total secara positif, (2) \\
\hline & mahasiswa memiliki bekal kecerdasan digital sesuai dengan \\
\hline & $\begin{array}{l}\text { karakter positif bangsa yang dibutuhkan, (3) mahasiswa mampu } \\
\text { berkontribusi dalam menumbuhkan citra positif Indonesia di mata }\end{array}$ \\
\hline & internasional. Rangkaian kegiatan berlangsung selama enam \\
\hline & bulan, mulai dari eksplorasi hingga distribusi konten video yang \\
\hline & 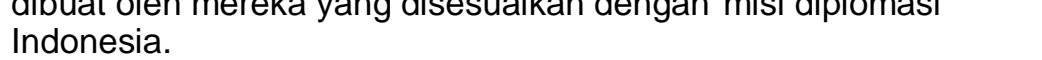 \\
\hline
\end{tabular}




\section{PENDAHULUAN}

Era digital turut mendorong arus informasi bergerak secara cepat. Perkembangan teknologi ini pun turut menggeser pola-pola interaksi yang terjalin antar aktor hubungan internasional. Jika dalam dipomasi tradisional aktor hubungan internasional condong pada state actor, kini di era diplomasi modern aktor hubungan internasional juga bisa diperankan non state actor (publik).

Pemerintah sebagai actor First track diplomacy memegang peranan penting sebagai pelaku utama dalam kegiatan diplomasi. Namun, aktor lain juga tak kalah penting untuk mendukung kesuksesan diplomasi ini. Pada Second track diplomacy, upaya-upaya diplomasi dapat dilakukan oleh elemen-elemen nonpemerintah secara tidak resmi (unofficial). Salah satu yang dapat berperan dalam second track diplomacy ini adalah masyarakat umum. Pada dasarnya, setiap orang yang menjalin hubungan secara internasional merupakan pelaku second track diplomacy tersebut (Nurwahyudi, 2017). Di era digital dan kehadiran teknologi yang semakin mengaburkan batas negara ini, diplomasi turut mengalami perkembangan. Diplomasi yang dilangsungkan suatu negara harus mampu menyesuaikan diri dengan perkembangan zaman. Salah satu yang bisa dilakukan ialah dengan optimalisasi Teknologi dalam diplomasi.

Menurut Menteri Luar Negeri Indonesia, Retno Marsudi, teknolgi digital dapat dimanfaatkan sebagai sarana diplomasi Indonesia. Salah satu yang bisa digunakan adalah dengan pendekatan melalui media sosial yang banyak dipakai oleh generasi millennial. Tak bisa dipungkiri bahwa perkembangan teknologi membuat generasi muda semakin intens dalam komunikasi dan lebih mudah dalam melakukan interaksi internasional. Untuk itu, dibutuhkan ara berbeda yang bisa menyambungkan berbagai kepentingan tersebut (Astarini, 2018). Lebih lanjut, Retno menyampaikan bahwa sebaran informasi secara global akan lebih efisien dan efektif dengan pendekatan anak muda, yakni melalui media sosial. Kondisi inilah yang memunculkan perkembangan kajian baru dalam hubungan internasional, yakni berupa digital diplomacy. Untuk dapat terlibat dalam digital diplomacy ini, seseorang tidak harus berprofesi sebagai diplomat, juga tidak harus menjadi sarjana hubungan internasional. Siapa pun dapat aktif terlibat dalam digital diplomacy ini (Astarini, 2018).

Salah satu langkah sederhana yang dapat dilakukan dalam pemanfaatan media digital dalam diplomasi ini adalah dengan menuliskan hal-hal baik mengenai 
Indonesia di media sosial. Hal ini akan turut membangun citra positif Indonesia sehingga pada akhirnya ikut menyukseskan tujuan diplomasi nasional. Hal-hal positif mengenai Indonesia dalam disebarluaskan oleh siapa pun ke seluruh dunia, dan ini menjadi bagian dari diplmasi total Indonesia.

Total diplomacy sendiri pada hakekatnya merupakan bentuk diplomasi yang dilakukan, dapat secara formal maupun informal, dan dengan melibatkan banyak pihak, sehingga tidak hanya antara pemerintah dengan pemerintah saja, melainkan bisa dilakuakn oleh pihak swasta dan masyarakat, melalui jaringanjaringan informal (Wangke, 2016 : 5). Melalui skema total diplomasi inilah, para pemuda Indonesia yang lebih akrab dengan perkembangan teknologi seharusnya mampu mengambil perannya dalam usaha mendukung diplomasi Indonesia ke arah positif.

Untuk itu, adalah hal penting jika setiap pemuda yang memanfaatkan media digital ini mampu memiliki kecerdasan digital yang kuat. Kecerdasan digital berarti seseorang harus mampu menggunakan media digital dengan berbagai pertimbangan dalam rangka mewujudkan bangsa yang berbudaya dengan berdasar pada nilai-nilai religius, jujur, toleran, mandiri, demokratis, disiplin, bekerja keras, kreatif, rasa ingin tahu, semangat kebangsaan, komunikatif, cinta damai, cinta tanah air, menghargai prestasi, gemar membaca, peduli lingkungan, peduli sosial, dan bertanggung jawab (Putri, 2018).

Atas dasar pentingnya kecerdasan digital bagi para pemuda yang saat ini banyak terlibat dalam skema total diplomacy Indonesia inilah, dirasa perlu untuk memberikan perhatian khusus bagi masalah ini. Salah satu kelompok yang dianggap membutuhkan pembekalan dalam kecerdasan digital terkait total diplomacy adalah para mahasiswa Hubungan Internasional. Sebagai mahasiswa Hubungan Internasional, diharapkan mereka memiliki bekal pemahaman yang mendalam terkait pola hubungan interasional dan mampu terlibat aktif dalam usaha mencapai tujuan diplomasi Indonesia.

Program pengabdian pada masyarakat ini dilaksanakan untuk mendukung para mahasiswa HI di wilayah Perguruan Tinggi Universitas Slamet Riyadi sebagai agen diplomasi bangsa yang positif. Program pengabdian pada masyarakat ini akan berusaha untuk memberikan kontribusi bagi usaha pemerintah dalam mendorong penguatan kecerdasan digital pemuda sebagia bentuk keterlibatan dalam total diplomasi Indonesia. 


\section{RUMUSAN MASALAH}

Pemuda dapat mengambil peran besar dalam mencapai total diplomacy Indonesia. Untuk itu, mengoptimalkan peran pemuda dalam digital diplomacy adalah hal penting. Para pemuda dapat didorong untuk cerdas secara digital sehingga dapat berkontribusi positif dalam menyukseskan diplomasi Indonesia. Program pengabdian pada Masyarakat ini dilakukan untuk menjawab permasalahan terkait hal tersebut, sehingga dapat mendukung upaya penguatan kecerdasan digital pemuda sebagai bentuk keterlibatan dalam total diplomasi Indonesia.

\section{METODE PENELITIAN}

Kelompok sasaran dalam program pengabdian masyarakat ini adalah para mahasiswa IImu Hubungan Internasional, Fakultas IImu Sosial dan IImu Politik, Universitas Slamet Riyadi Surakarta. Para mahasiswa HI dipilih sebagai mitra sasaran karena dianggap sebagai sosok agen pembangunan yang paling tepat dan membutuhkan bekal untuk total diplomacy, mengingat bekal diplomasi yang telah diperoleh dari bangku perkuliahan. Metode pelaksanaan berupa pemberian sosialisasi dan pelatihan kepada para mahasiswa. Sosialisasi dilakukan dengan memberikan materi terkait pentingnya keterlibatan masyarakat dalam total diplomasi Indonesia, dan kontribusi apa saja yang bisa mereka perankan. Tahapan pelaksanaan meliputi: tahap sebelum pelaksanaan, yang pada tahap ini dilakukan analisis masalah dan situasi mitra serta pertimbangan solusi. Tahap selanjutnya adalah pembekalan dan koordinasi bagi pihak- pihak yang terlibat dalam kegiatan ini yaitu para dosen dan mahasiswa sebagai kelompok sasaran. Tahap selanjutnya adalah tahap pelaksanaan yang dilakukan pada tahap ini, adalah dengan sosialisasi, meliputi pemahaman kecerdasan digital yang penting dimiliki dalam era digital seperti sekarang ini. Selanjutnya, ada kegiatan diskusi dan tanya jawab. Tahap selanjutnya, para mahasiswa diajak untuk merealisasikan bekal ilmu yang telah diperoleh untuk mendukung total diplomasi Indonesia, yakni dengan membuat video kampanye bertema Social Development Goals secara berkelompok. Tahap terakhir, adalah pembuatan laporan.

\section{PEMBAHASAN}


Program sosialisasi dan pelatihan dilakukan dengan cara tatap muka langsung di kelas. Hal ini bertujuan untuk memperluas wawasan para mahasiswa, baik yang sudah mulai melakukan kegiatan total diplomasi maupun yang belum, dengan memberikan gambaran mengenai bagaimana mengembangkan kecerdasan digital dengan berlandaskan pada karakter moral bangsa yang positif. Dalam pelatihan juga diberikan bagaimana cara ideal mengemas pesan secara audio visual agar konten dalam sosial media dapat berguna dalam mendukung total diplomasi Indonesia dan membantuk citra positif bangsa.

Adapun jadwal realisasi pelaksanaan sosialisasi dan pelatihan program pengabdian masyarakat, ini yakni pada hari Jumat, tanggal 17 Mei 2019 pukul 19.00 - 15.00, bertempat di Ruang Multimedia, Unisri Surakarta, dengan jumlah peserta 40 orang. Pemaparan materi dilakukan dengan menyesuaikan pada kebutuhan dan kondisi peserta pengabdian, sesuai dengan hasil penjajagan yang didapat. Pemaparan bertujuan untuk memberi gambaran bagi para mahasiswa HI akan pentingnya pengembangan skill dalam menjalankan diplomasi total. Kegiatan ini sekaligus diharapkan agar dapat mendorong mahasiswa lebih termotivasi untuk turut berkontrbusi dalam mempromosikan citra positif bangsa Indonesia lewat media sosial.

\section{Gambar 1. Sosialisasi Kecerdasan Digital}

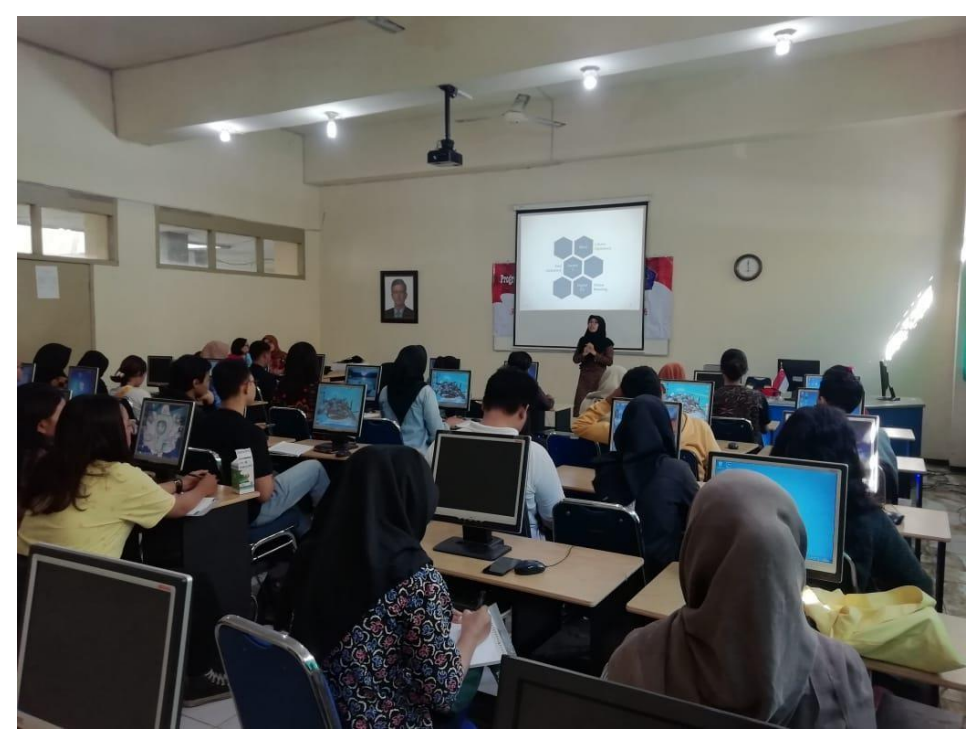

Gambar 2. Pelatihan Video untuk Konten Total Diplomasi 


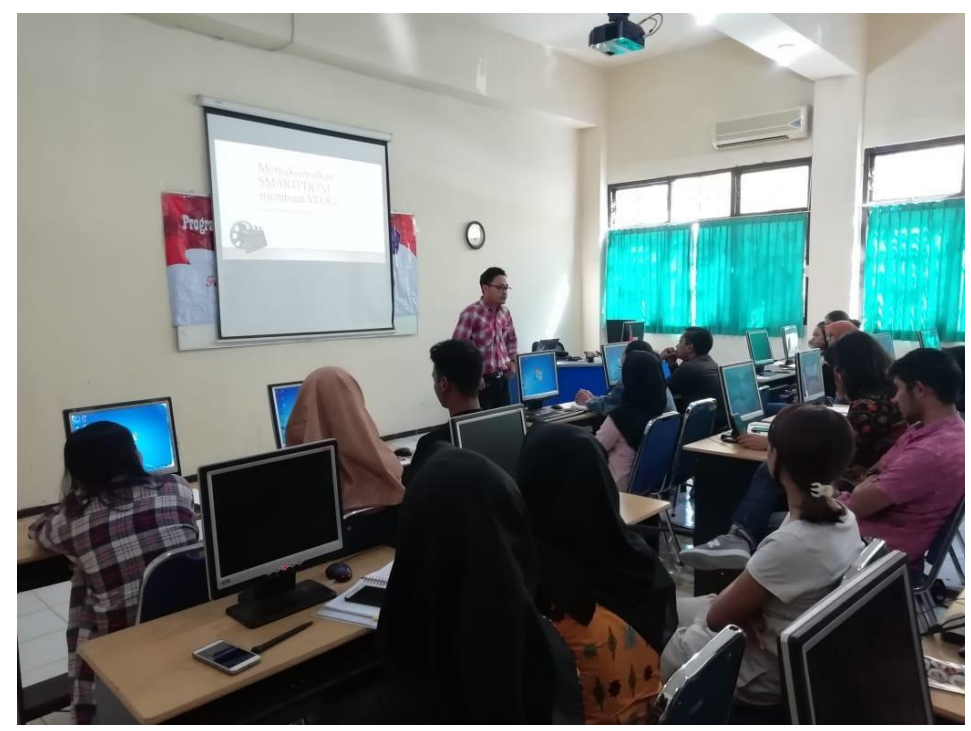

Selama ini, para mahasiswa banyak yang menggunakan media sosial, akan tetapi tidak memperhatikan etika dan landasan moral dalam menggunakan sosial media tersebut. Pada akhirnya, para pemuda akan memanfaatkan sosial media secara serampangan. Bahkan, mereka tidak menyadari bahwa kegiatannya dapat berkontribusi dalam total diplomasi Indonesia. Untuk itu, mereka perlu diberi pembekalan sehingga siap dan memiliki informasi yang cukup terkait kecerdasan digital. Kecerdasan digital yang ideal akan membantu mereka dalam memanfaatkan media sosial secara bijak. Sekaligus, mereka diajak serta untuk bisa berkontribusi dalam total diplomasi Indonesia. Atas dasar hal ini pula, para pemuda perlu ditingkatkan motivasi dan pemahamannya mengenai kondisi interaksi hubungan internasional secara global untuk mengembangkan diri dan mengembangkan citra positif bangsa. Apalagi, di era perkembangan digital seperti sekarang ini, kesempatan untuk terlibat dalam interakasi global semakin terbuka lebar. Pendampingan dan motivasi dilakukan setelah kegiatan sosialisasi dan pelatihan, bersamaan dengan pemberian tugas untuk membuat video yang memuat konten total diplomasi.

Praktek pembuatan video diplomasi dilakukan dengan target luaran berupa video-video dengan konten yang mendukung skema total diplomasi Indonesia. Jadi, para mahasiswa dari kelompok sasaran dibuat berkelompok dan mendapat amanat untuk membuat video. Masing-masing kelompok harus membuat video yang terkait misi SDGs (Social Development Goals). Selama prosesnya, mahasiswa didampingi dan dilatih agar konten video yang dibuat menarik serta sesuai dengan target. 
Program pengabdian kepada masyarakat dengan tema "penguatan kecerdasan digital pemuda sebagai bentuk keterlibatan dalam total diplomasi Indonesia" diharapkan mampu memberikan hasil yang positif dalam rangka mendukung upaya Pemerintah dalam meningkatkan citra positif bangsa Indonesia di mata internasional. Para pemuda sebagai agen bangsa bisa menjadi para diplomat bangsa sebagai non state actor. Sebab, dalam skema total diplomasi, tidak hanya oara diplomat yang mendapat mandat resmi dari negara saja yang diharapkan menjalankan diplomasi untuk kepentingan Indonesia. Setiap elemen bangsa pun bisa turut berkontribusi dan mengambil bagian dalam diplomasi Indonesia.

Diplomasi modern dijalankan dengan konsep yang semakin fleksibel dan dengan alat-alat yang fleksibel pula. Keberadaan teknologi digital yang semakin masif memungkinkan untuk dijadikan sebagai salah satu sarana diplomasi. Dalam hal ini, para pemuda, khususnya kelompok sasaran, yakni mahasiswa Hubungan Internasional Unisri didorong untuk bisa memahami perannya dalam total diplomasi ini. Tak hanya itu, mereka diajak serta agar meningkatkan kontribusinya dalam diplomasi Indonesia.

Dalam kegiatannya, diperoleh gambaran bahwa kegiatan pengabdian ini memang sangat penting bagi kelompok sasaran. Alasannya, kelompok sasaran merupakan generasi native digital. Artinya, mereka sangat akrab dengan penggunaan teknologi digital dalam kehidupan mereka sehari-hari. Hanya saja, mereka menggunakan teknologi tersebut secara apa adanya. Tidak ada informasi yang cukup terkait pemaksimalan pemanfaatan teknologi digital. Apalagi, sebagai mahasiswa hubungan internasional, mereka tidak menyadari bahwa mereka bisa menjadi para diplomat bangsa melalui teknologi digital ini.

Berkaca dari informasi yang diperoleh dari hasil penjajagan tersebut, tim pengabdian melakukan sosialisasi dan pelatihan. Para mahasiswa dijelaskan mengenai pentingnya upaya pemanfaatan teknologi digital secara positif. Mereka juga diberi gambaran hal-hal apa saja yang bisa mereka lakukan dalam rangka mendukung tujuan nasional bangsa Indonesia melalui teknologi digital. Proses sosialisasi dan pelatihan berjalan lancar. Para mahasiswa sebagai kelompok sasaran menyambut antusias terkait informasi yang mereka terima. Mereka pun menyatakan bahwa informasi tersebut bermanfaat. 
Ketika dilangsungkan tanya jawab, para mahasiswa secara interaktif menanyakan berbagai hal yang masih dianggap kurang jelas. Mereka tertarik untuk turut berkontribusi aktif dalam mendukung peningkatan citra positif bangsa. Pelatihan terkait pembuatan konten diplomasi juga disambut antusias. Selanjutnya, mereka menerima tugas pembuatan video juga dengan senang hati. Setelah acara sosialisasi dan pelatihan selesai, para mahasiswa tetap didampingi dan dipantau dalam proses pembuatan konten diplomasi berupa video.

Masing-masing kelompok melakukan sesi pengambilan konten video sesuai tema yang dipilih, yang masih berada dalam lingkup SDGs. Beberapa bahkan rela pergi bolak balik ke luar kota Solo untuk mengumpulkan konten video. Beberapa kelompok lain, terjun ke masyarakat seperti di dalam pasar dan di kantor pemerintahan untuk mengumpulkan konten. Selanjutnya, materi tersebut mereka rangkum dalam bentuk video bermuatan diplomasi. Video dibuat dengan menggunakan audio bahasa Indonesia dan bersubtitle bahasa Inggris, atau dengan audio bahasa Inggris dan subtitle bahasa Indonesia. Adapun total durasi proses pembuatan video berlangsung selama kurang lebih dua bulan.

Dari deskripsi hasil yang telah disampaikan, diketahui bahwa sesungguhnya kelompok sasaran memiliki minat untuk bisa mendukung total diplomasi Indonesia. Hanya saja, selama ini mereka tidak menyadari bahwa dalam konsep total diplomasi, mereka bisa berkiprah dalam hal tersebut. Mereka telah mempelajari apa itu diplomasi dan bagaimana diplomais berkembang dengan segala dinamikanya. Informasi terkait total diplomasi pun sudah diperoleh. Namun, langkah nyata yang bisa dilakukan tiap-tiap individu untuk total diplomasi ini yang masih membingungkan mereka. Mereka masih ragu bahwa mereka pun bisa ikut terlibat dalam diplomasi aktif Indonesia.

Diplomasi modern memungkinkan setiap individu warga negara untuk bisa terlibat dalam kegiatan diplomasi. Berbagai jalur dan media bisa ditempuh sesuai kemampuan dan kebutuhan. Artinya, sesungguhnya para mahasiswa dengan kemampuan dan keaktifannya bermain media sosial pun bisa menjadi bentuk total diplomasi. Cara yang paling sederhana adalah dengan menuliskan hal-hal positif tentang Indonesia dan membuat dunia mengetahui bagaimana citra positif bangsa Indonesia. Turut mendukung nama baik Indonesia dan mempromosikan Indonesia ke dunia internasional juga menjadi bagian dari total diplomasi. 
Peran mahasiswa dalam mendukung kegiatan diplomasi ini dapat memberikan keuntungan bagi bangsa. Apalagi, bila gerakan ini dilakukan dalam jumlah yang cukup banyak. Tentunya efeknya akan semakin besar. Ketika masing-masing kelompok mahasiswa menghasilkan konten video yang mampu menyasar publik internasional, mereka sudah terlibat dalam diplomasi Indonesia. Informasi positif tentang bangsa akan menambah nilai positif bangsa Indonesia. Selain itu, rasa cinta terhadap tanah air juga akan meningkat.

Konten-konten video yang dibuat mahasiswa menunjukkan bahwa mereka memiliki antusias dan menyambut positif program ini. Untuk memastikan bahwa konten video tersebut telah memenuhi harapan, tim pengabdian melakukan pemeriksaan konten video tersebut. Masing-masing hasil video disaksikan bersama dan diberi masukan untuk memperbaiki jika masih ada yang kurang pas. Selanjutnya, konten video tersebut dipersilakan untuk disebar di media sosial agar bisa tersampaikan di kalangan masyarakat internasional.

\section{CONCLUSION}

Kecerdasan digital di era globalisasi yang semakin banyak mengandalkan produk digital seperti sekarang ini adalah hal penting. Untuk itulah, pemerintah berusaha untuk mencapai total diplomasi secara efektif. Bagi para pemuda, memiliki kecerdasan digital sudah menjadi hal penting agar mereka bisa berkontribusi positif dan terlibat aktif dalam mendukung total diplomasi yang ditargetkan pemerintah Indonesia. Kegiatan sosialisasi dan pelatihan sebagai program pengabdian ini telah dilaksanakan dengan baik, dengan kelompok sasaran para mahasiswa IImu Hubungan Internasional, Unisri. Jumlah mahasiswa kelompok sasaran yang mengikuti program ini adalah 40 orang. Program pengabdian dilaksanakan melalui beberapa tahapan proses, mulai dari pengabdian, sosialisasi dan pelatihan serta pembuatan konten video.

Dalam tahap persiapan, tim pengabdian berupaya menggali kebutuhan dan kondisi dari kelompok sasaran secara detail. Selanjutnya, sosialisasi dan pelatihan disesuaikan dengan kebutuhan kelompok sasaran. Adapun pelaksanaan sosialisasi dan pelatihan dilangsungkan selama satu hari pada tanggal $17 \mathrm{Mei}$ 2019. Para mahasiswa tetap didampingi dalam rangka pembuatan konten video, sebagai wujud nyata kontribusi mereka dalam total diplomasi Indonesia. Proses 
pembuatan video berlangsung selama dua bulan. Selanjutnya, video disaksikan dan dikoreksi bersama, dan berikutnya disebarkan melalui media sosial

\section{REFERENCES}

Astarini, Dwi. 2018. Digital Diplomatik, Gaya Diplomasi Millennial. MerahPutih dalam https://merahputih.com/post/read/digital-diplomatik-gayadiplomasi-millennial

Nurwahyudi, Aziz. 2017. "Peran Pemuda dalam Diplomasi" dalam seminar kepada finalis PPAN Jakarta 2017 dalam kegiatan Pre-Departure Training (PDT) di DISORDA DKI Jakarta, Sabtu, 22 April 2017

Putri, Melda Widia. 2018. Strategi Mendidik Generasi Milenial di Zaman Global, diakses dari http://tanjungpinangpos.id/strategi-mendidik-generasimilenial-di-zaman-global/

Wangke, Humphrey. 2016. Keberhasilan Diplomasi Total. Majalah Info Singkat Hubungan Internasional, Vol. VIII, No. 10/II/P3DI/Mei/2016 